\title{
Abordagens de governança em áreas metropolitanas da América Latina: avanços e entraves
}

\author{
Approaches of metropolitan governance in Latin \\ America: advances and obstacles
}

Klaus Frey

Doutor em Ciências Sociais, Universidade Federal do ABC (UFABC), Centro de Engenharia, Modelagem e Ciências Sociais Aplicadas (CECS), Programa de Mestrado em Planejamento e Gestão do Território, Santo André, SP - Brasil, e-mail: klaus.frey@ufabc.edu.br

\section{Resumo}

Este artigo discute alguns aspectos empíricos e teórico-conceituais das transformações das estruturas e práticas de governança em áreas metropolitanas na América Latina. Inicia-se com os problemas e desafios que se colocam na atual conjuntura para a governança das regiões metropolitanas, para, na sequência, examinar algumas mudanças institucionais ocorridas na América Latina nas últimas décadas. Maior ênfase é dada aos casos emblemáticos e antagônicos do Brasil e da Colômbia, sendo o primeiro caracterizado por uma inserção num Estado federativo com forte autonomia municipal e uma - de fato - omissão por parte do Estado nacional quanto às regiões metropolitanas; e o segundo pelo papel crucial exercido pelo Estado central na busca da criação de uma governabilidade metropolitana, no contexto de um sistema estatal unitário com autoridades locais frágeis. A partir dessa contraposição, possíveis estratégias institucionais alternativas são discutidas, sobretudo as possibilidades de novas práticas interativas de cooperação em rede no âmbito da governança metropolitana. Por fim, são apresentados alguns desafios da governança metropolitana na América Latina visando promover práticas políticas mais interativas e democráticas entre as autoridades estatais e a sociedade civil.

Palavras-chave: Governança metropolitana. Arranjos institucionais. Cooperação em rede. América Latina.

\section{Abstract}

This article addresses some empirical and theoretical aspects of changing governance structures and practices in Latin American metropolitan areas. It starts with the problems and challenges faced by metropolitan governance in the current context. Subsequently, some institutional changes in Latin America in recent decades are examined, placing greater emphasis on the emblematic and antagonistic cases of Brazil and Colombia: the first being characterized by a federal state with strong local autonomy and evident shortcomings of national state initiatives concerning its metropolitan regions; the second for the crucial role played by the central 
government in the pursuit of metropolitan governance in the context of a unitary state system with relatively weak local authorities. Based on this confrontation, possible alternative institutional strategies are discussed, especially the possibilities of new interactive practices of network cooperation within an overall framework of metropolitan governance. Finally, the paper concludes with some challenges of metropolitan governance in Latin America in order to promote more interactive and democratic political practices between state authorities and civil society.

Keywords: Metropolitan governance. Institutional arrangements. Network cooperation. Latin America.

\section{Introdução}

Durante as últimas décadas, as metrópoles latino-americanas sofreram transformações graves no que tange à expansão territorial e ao agravamento dos problemas sociais, bem como a deficiências em termos de infraestrutura básica e à exploração de oportunidades econômicas, tornando-se cada vez mais necessárias respostas coletivas e verdadeiramente metropolitanas a esses novos desafios que se colocam para o bem-estar das populosas regiões metropolitanas.

No entanto, como tratar, organizar, gerenciar e planejar aglomerações metropolitanas caracterizadas por um aumento contínuo da complexidade? Como lidar com as tendências de gentrificação e fragmentação urbana, com a crescente diversidade espacial, social e econômica, a distribuição desigual da infraestrutura urbana e as ameaças relativas à qualidade ambiental e às condições de vida da população nessas regiões? Como abordar a progressiva dependência de fatores externos como a vacilante economia mundial ou as mudanças ambientais globais? Como responder ao desafio de articular a ação pública em diferentes escalas, bem como diferentes espaços territoriais e funcionais? Sem dúvida, são imprescindíveis novas respostas articuladas e interescalares e um papel mais ativo exercido pelas metrópoles ou cidades regiões, colocando em destaque o conceito da governança em áreas metropolitanas ${ }^{1}$.

Não por acaso, a noção de governança ganhou importância e foi inicialmente concebida como uma abordagem teórica e analítica para compreender as novas formas e práticas de articulação político-administrativa que surgiram relacionadas, por um lado, à influência política crescente da União Europeia e, por outro, ao processo de metropolização (GROTE; GBIKPI, 2002; HAMBLETON et al., 2002; HEINELT, 2008). Ambos os casos têm em comum que as estruturas institucionais, legalmente instituídas, revelaram-se incapazes ou insuficientes para incorporar as emergentes redes político-administrativas, primordialmente informais e compostas por atores de autoridades estatais, do setor produtivo e das organizações não governamentais, que crescentemente marcam o ambiente político-administrativo nas sociedades mais complexas e diversificadas.

No passado, as relações informais na arena política, consideradas como característica peculiar da política latino-americana, têm sido muitas vezes consideradas como patologias do processo político: ou como expressão de um tipo obsoleto de cultura política, caracterizada pelo patrimonialismo, clientelismo e a corrupção, ou, pelo menos, como entrave na busca de uma prática política moderna e racional. No entanto, no debate contemporâneo sobre governança esta informalidade ganha importância, vista agora como uma necessidade urgente, em razão dos deficits de eficácia da ação meramente estatal, da falta de capacidade das autoridades públicas em dar respostas às crescentes demandas sociais e, finalmente, da observada perda de legitimidade democrática das estruturas e processos políticos

\footnotetext{
1 Recorrendo ao conceito de governança metropolitana, não pretendemos restringir nossa análise a processos e instituições de governança em regiões metropolitanas formalmente estabelecidas. Estamos antes interessados na compreensão dos avanços e dificuldades nos processos de articulação e cooperação entre diferentes atores governamentais e não governamentais no enfrentamento coletivo de problemas comuns, sendo condicionados por instituições formais ou informais e caracterizados por problemas envolvendo dimensão supramunicipal ou metropolitana.
} 
formais. Todavia, o principal dilema inerente ao conceito teórico de governança e seus correspondentes fenômenos empíricos está relacionado à possibilidade de que a abertura para a informalidade e flexibilidade institucional na política - mesmo se considerada inevitável no contexto atual - poderia levar a uma revitalização dos bem conhecidos vícios e patologias da política latino-americana.

Então, se partimos do pressuposto de um inevitável alinhamento de processos e instituições políticos à necessidade de uma ação pública coordenada, perpassando múltiplas escalas e setores e promovendo destarte padrões mais flexíveis e interativos de articulação política, um debate mais amplo sobre as necessidades institucionais de governança metropolitana é necessário, sem, contudo, ignorar os riscos relacionados à informalidade política.

Neste artigo são discutidos alguns aspectos empíricos e teórico-conceituais das mudanças em curso na América Latina na área da governança em áreas metropolitanas. A partir de uma contextualização inicial abordando problemas e desafios colocados na atual conjuntura para a governança em áreas metropolitanas, o artigo examina algumas mudanças institucionais ocorridas na América Latina nas últimas décadas, bem como possíveis estratégias institucionais alternativas. Por fim, são incluídos alguns desafios da governança metropolitana na América Latina visando promover práticas políticas mais interativas entre as autoridades estatais e a sociedade civil.

\section{A metropolização e o desafio da governança}

Nas últimas décadas, as cidades latino-americanas sofreram transformações significativas, problemas antigos e novos, em um contexto de um "processo de metropolização cada vez mais denso, concentrado e complexo" (SANTOS Jr., 2009, p. 7). Os desafios metropolitanos relacionados ao aumento da pobreza, à segregação social e territorial, à deterioração do meio ambiente e da qualidade de vida, ao aumento da violência e da criminalidade, para mencionar só alguns, tipicamente perpassam e não se atêm às fronteiras político-administrativas. No entanto, enquanto, por um lado, são marcados por fortes conflitos de interesses e dilemas de ação coletiva, por outro, envolvem potencialidades de "spillovers", que a princípio favorecem, ou demandam, atuações coletivas dos diferentes órgãos e atores afetados (FEIOCK, 2004); ou seja, a perspectiva de possíveis ganhos individuais em virtude de ações coordenadas impulsiona esses agentes para a cooperação e ação coletiva, tornando crucial a ampliação da "capacidade de articular escalas, de analisar e intervir de modo transescalar" (VAINER, 2006, p. 28).

Contudo, a governança metropolitana ultrapassa a mera necessidade de criar uma instância de planejamento em nível regional dotada de competências e capacidades para garantir uma racionalidade técnica supostamente superior para melhor enfrentar os dilemas de ação coletiva relacionados à fragmentação das competências jurisdicionais. Além da dimensão horizontal, da necessidade de integração e coordenação da ação intermunicipal, governança metropolitana também abrange a necessidade de uma articulação na dimensão vertical, tanto "para baixo" (em direção às esferas espaciais das vizinhanças e bairros) como também "para cima" para os níveis superiores, sejam estes os níveis do estado, da União ou em relação a arranjos institucionais internacionais (HEINELT, 2008, p. 159). As tendências gerais de fragmentação e complexificação, que muitas vezes fogem das competências e do alcance da ação meramente municipal, dificultam a perseguição de políticas e estratégias intermunicipais comuns e integradoras ou de estratégias verdadeiramente metropolitanas, no sentido de contemplar suas dimensões tanto horizontais quanto verticais.

Apesar das limitações da questão metropolitana nos processos de redemocratização na América Latina, o debate sobre governança metropolitana voltou a ganhar relevância nos últimos anos em função do crescente reconhecimento da importância dessas regiões para o processo geral de desenvolvimento econômico. Destarte, as experiências latino-americanas de governança metropolitana e o respectivo discurso, ainda bastante incipientes, seguem "a mais nova onda de reformas de governança metropolitana [... em toda a Europa ocidental que...] é focada nas prioridades econômicas como a competitividade territorial e em atrair capital externo de investimento no contexto da integração geoeconômica e Europeia" (BRENNER, 2003, p. 297).

As experiências europeias, de acordo com Brenner, só podem ser compreendidas considerando-se, por um lado, as tendências mais amplas de redimen- 
sionamento do Estado em termos territoriais, relacionadas principalmente ao processo de integração europeia, e, por outro, a relação de tais experiências com "novas emergentes estratégias políticas visando à reconfiguração das abordagens herdadas em favor de uma governança urbana empreendedora" (BRENNER, 2003, p. 297).

Visto que na América Latina, e especificamente no caso brasileiro, o último aspecto tem igualmente ganhado relevância na governança urbana no decorrer das últimas décadas (ARANTES et al., 2000; COPANS, 2005; DE MATTOS, 2004; FREY, 2007), outros aspectos são importantes para se entender o renovado interesse na reconfiguração do Estado: em primeiro lugar, o debate sobre a necessidade de um novo pacto federativo, a redefinição das competências entre os três níveis de governo e a necessidade de uma melhorada cooperação federativa nas políticas públicas (ARRETCHE, 1999; ABRUCIO, 2005); e segundo, os problemas metropolitanos estruturais que recolocaram na agenda política as estratégias de recentralização política e administrativa (DAVIDOVICH, 2004; ROLNIK, SOMEKH, 2003).

Os receios relacionados ao fortalecimento da escala metropolitana estão, portanto, tradicionalmente relacionados à possibilidade de um enfraquecimento do poder local - espaço privilegiado de mobilização e organização social e política - e, com isso, da própria democracia. Tendo em vista que os avanços em termos de democratização, ampliação da participação popular e fortalecimento da sociedade civil concentram-se basicamente em âmbito municipal, não parecem sem fundamento os temores acerca dos potenciais riscos relacionados à recentralização e tecnocratização que poderiam acompanhar o fortalecimento institucional em nível metropolitano. Cabe ressaltar que as medidas de descentralização na América Latina devem ser compreendidas como "reação à metrópole, como resistência ao centralismo do poder" (DAVIDOVICH, 2004, p. 203), historicamente dominante na região. Por isso, o fortalecimento do poder local nas últimas décadas na América Latina foi primordialmente visto como conquista democrática, opondo-se aos períodos de maior institucionalização em nível metropolitano que tradicionalmente convergiu com padrões governamentais centralistas e autoritários.

Todavia, análises do federalismo brasileiro pós-Constituição revelaram também "os efeitos perversos da descentralização" (MELO, 1996), baseados na dominação das elites locais e de práticas patrimonialistas e clientelistas, bem como no aumento da competitividade nas relações intermunicipais em detrimento dos princípios da cooperação e solidariedade. As discussões acerca da "volta da metrópole" (DAVIDOVICH, 2004) ou "da escala pertinente da ação política e de planejamento" (VAINER, 2006, p. 9) precisam, portanto, levar em consideração a pluralidade dos arranjos institucionais, as diferenças e os dilemas da(s) cultura(s) político-administrativa(s), assim como os interesses políticos em jogo e as respectivas dinâmicas políticas subjacentes.

A preponderância da dimensão econômica e da competividade regional é uma das novas variáveis presentes nas recentes tentativas de revitalizar a discussão em torno das regiões metropolitanas, e tem como premissa e consequência a mobilização e a maior representação do empresariado local em fóruns de desenvolvimento regional e, consequentemente, o ajustamento aos interesses da elite política e econômica local: "As alternativas estratégicas podem variar [...], mas a fórmula escolhida tem que ser aceitável e viável para o estamento político que, no final das contas, representa os interesses dos cidadãos, dos agentes econômicos e sociais" (CUADRADO-ROURA; GÜELL, 2005, p. 120).

Esse argumento de uma suposta equivalência entre os interesses dos cidadãos e os de seus representantes parte da premissa da eficácia do princípio da representação no processo democrático; uma premissa bastante questionável no contexto latino-americano, no qual a relação entre as classes ou elites políticas dominantes e as massas populacionais é habitualmente marcada por patrimonialismo, clientelismo e corrupção como padrões comuns de comportamento político.

Abordagens consensualistas, perseguidas em contextos de sociedades desiguais e de graves desequilíbrios de poder, frequentemente implicam na exclusão de atores sociais incômodos dos processos decisórios, na "imposição de consensos" e na busca de determinação de uma agenda hegemônica por parte dos atores mais influentes no processo; ou busca-se atenuar o conflito pela constituição de agendas e processos políticos paralelos, atendendo diferentes clientelas e interesses em jogo, privilegiando 
a fragmentação do processo político e, logo, sua despolitização.

De fato, as pressões da globalização limitam as possibilidades de ação por parte da governança urbana (GILBERT, 2003), e em função da fixação dos atores políticos dominantes nas oportunidades proporcionadas pelo mercado global, multiplicam-se ainda mais as tendências de fragmentação e segregação urbana:

A necessidade de posicionar-se nos mercados internacionais e de atrair empresas vinculadas à economia global reforça a tendência de criar zonas "especiais", parques tecnológicos e empresariais, World Trade Centers ou centros de telecomunicações etc., que muitas vezes podem constituir verdadeiros enclaves, sem efeitos de integração, nem com relação à cidade, nem talvez em relação à economia (BORJA, 2001, p. 23).

As segregações econômicas, na sua dimensão espacial, reforçam a polarização social, acarretando consequências graves para a qualidade de vida das pessoas (REICHL, 2007), fato que coloca a governança local no centro de atenção: "interações locais entre os cidadãos e o Estado se tornaram mais importantes e mais críticas para as atuais condições de vida e as oportunidades futuras de milhões de cidadãos" (GRINDLE, 2007, p. 5). E é nessas interações que ganha destaque o nível regional ou metropolitano dentro de uma concepção de governança que aposta antes na cooperação e integração em favor de um desenvolvimento sustentável da região do que na competição municipal pela atração de recursos escassos, ou seja, que valoriza "a cooperação em detrimento do individualismo localista" (ROLNIK; SOMEKH, 2003, p. 103).

Partimos da suposição de que a habitual forma dualística e fragmentária de pensar e de agir deve ser considerada como um dos impedimentos principais no caminho em direção à maior sustentabilidade social e ambiental urbana. Um dos grandes desafios da governança metropolitana se refere, portanto, à difícil inclusão da dimensão popular, por meio de mecanismos participativos efetivamente democráticos nos processos decisórios metropolitanos e regionais e, logo, exige que "a questão da polarização pode reformular a substância do discurso político e alterar a agenda urbana" (REICHL, 2007, p. 660).
A governança metropolitana não pode se restringir, em nosso entender, a um arranjo apolítico objetivando um simples ajuste, supostamente "técnico", entre órgãos administrativos a fim de otimizar processos e projetos dentro de uma lógica meramente técnico-funcional, nos moldes como vem sendo conduzido o frágil processo de integração metropolitana na América Latina. Avanços na articulação metropolitana passam necessariamente pelo fortalecimento da política como instrumento fundamental de transformação.

A construção de uma efetiva governança em âmbito metropolitano ou regional, de caráter transescalar, intersetorial e democrático, exige inicialmente o reconhecimento do caráter político de tal empreendimento, a refutação de soluções tecnocráticas e, portanto, a promoção de arenas onde o embate entre as diferentes percepções e interesses possa ocorrer. Tudo isso, então, torna essencial uma melhor compreensão do processo de formação das mudanças institucionais em regiões metropolitanas.

\section{Mudanças institucionais: centralização versus descentralização}

Conforme afirma a Organisation for Economic Co-operation and Development (OECD, 2001, p. 16), "a descentralização reforçou a consciência da necessidade de melhorar a governança em nível metropolitano". Entretanto, os avanços em direção a um real fortalecimento do nível metropolitano como instância efetiva e ao mesmo tempo democrática, capaz de lidar com os complexos problemas econômicos, ambientais e sociais são bastante restritos. Até mesmo para os países da OECD, o relatório afirma que "em muitos países da OECD as áreas metropolitanas ainda funcionam com um mínimo de coordenação e de planeamento estratégico em nível local" (OECD, 2001, p. 17).

Ao analisar experiências de governança metropolitana na América Latina, Cuadrado-Roura e Güell (2005, p. 73) destacam a importância de se considerar as peculiaridades do contexto latino-americano: "as metrópoles latino-americanas apresentam certas características físicas, socioeconômicas e políticas que as diferencia do resto das áreas metropolitanas do planeta". Em termos institucionais, o caso latino-americano confirma a tendência global de 
omissão em termos de institucionalização de arranjos efetivos de governança metropolitana. Segundo Klink (2005, p. 176), na grande maioria dos casos, "as regiões metropolitanas da América Latina são carentes de uma estrutura madura e consolidada para a governança metropolitana capaz de enfrentar o desafio de criar competitividade urbana, sustentabilidade ambiental e melhor qualidade de vida".

Grande parte da literatura parte do pressuposto básico da necessidade de estruturas institucionais supramunicipais ou, ao menos, intermunicipais, para poder lidar adequadamente, do ponto de vista técnico, com os problemas funcionais das regiões metropolitanas. Condições favoráveis de accountability, no sentido de alcançar uma convergência entre as escalas de manifestação técnica de dados problemas e seu enfrentamento político-administrativo, devem permitir um processo consistente de controle social da ação pública.

Frequentemente, o governo metropolitano tem sido identificado com centralização e, por outro lado, o governo descentralizado com democracia (BARLOW, 1994). Isso também ocorreu na América Latina, sobretudo após o período dos regimes autoritários, quando a democracia local havia sofrido um processo de corrosão generalizada. 0 fortalecimento do municipalismo nas constituições democráticas posteriores, garantindo aos municípios - pelo menos legalmente - uma forte autonomia local, só é compreensível, como no caso brasileiro, enquanto resposta ao anterior regime centralista, num contexto global pró-democracia, privilegiando, entretanto, uma situação de omissão a respeito da escala metropolitana (ABRUCIO, 2005; SOUZA, 2007).

Como consequência dos dilemas funcionais que resultaram desses processos, recorreu-se, nos debates sobre desenvolvimento, frequentemente ao princípio da "subsidiariedade": as decisões devem ser tomadas nos níveis governamentais mais inferiores, ou seja, mais próximo possível do cidadão, embora exigências e características técnicas possam demandar estruturas supramunicipais, no caso de os problemas apresentarem uma clara relevância metropolitana ou regional (LEFÈVRE, 2005; ROJAS, 2010).

No entanto, justamente essa divisão vertical de responsabilidades parece cada vez menos factível, tendo em vista a complexidade dos problemas enfrentados e o aumento das "externalidades e transcendências" no território (ROJAS, 2010). As grandes aglomerações urbanas são caracterizadas por uma progressiva multiplicação de problemas que transcendem a jurisdição de unidades territoriais específicas, afetando diferentes espaços ou arenas político-administrativas concomitantemente. Nesse sentido, modelos abrangentes e idealizados se tornam cada vez menos consistentes diante da complexidade técnica e sociopolítica em jogo.

Do ponto de vista democrático, o confronto bastante simplista entre centralização e descentralização - identificando estruturas metropolitanas com centralização e autoritarismo e a autonomia municipal com descentralização - e democracia parece cada vez menos defensável, pelo menos se passarmos a adotar uma perspectiva diferenciada, observando para o nível metropolitano também como parte da estrutura do Estado nacional, e não, primordialmente, como estrutura intermediária imposta externamente com o objetivo principal de restringir a autonomia local.

Assim, impõe-se uma nova visão que percebe a escala metropolitana como possível resultado de um duplo processo de transferência de funções: do nível local ao metropolitano, mas concomitantemente, do âmbito estadual ou federal à escala metropolitana ou regional. A partir dessa perspectiva, "o governo metropolitano providencia a necessária centralização frente aos governos locais e a necessária descentralização frente aos governos de níveis superiores" (BARLOW, 1994, p. 328). Deste ângulo, a institucionalização em nível metropolitano - o que não implica necessariamente em governo metropolitano, conforme proposto por Barlow - ao invés de representar uma necessária perda de autonomia municipal, pode abrir espaços para uma retomada, por parte dos governos locais, de responsabilidades quanto aos destinos das regiões metropolitanas em virtude do envolvimento em processos de colaboração, negociação e cooperação no âmbito de arranjos institucionais supramunicipais.

Neste contexto, a consideração adicional de estruturas reticulares e informais parece indispensável, permitindo e favorecendo processos de cooperação, diálogo e colaboração entre e sobre diferentes escalas, jurisdições e setores. É esta perspectiva 
multinível da governança que ganhou importância nos debates europeus e norte-americanos, ao passo que na América Latina o debate sobre governança metropolitana parece ainda monopolizado pelas preocupações com a otimização técnico-funcional do planejamento físico-territorial.

Lefèvre (2005), por exemplo, apresenta o que ele chama de um "modelo ideal" de um "governo metropolitano", caracterizado por: eleições diretas de autoridades metropolitanas e, dessa maneira, politicamente legitimadas; um território jurisdicional que corresponde ao território funcional da metrópole; recursos financeiros próprios; responsabilidades e competências relevantes; e, finalmente, recursos humanos competentes para elaborar e executar políticas e ações relevantes. Dependendo do grau de cumprimento desses princípios, ele diferencia entre uma versão forte e uma fraca deste modelo de governo metropolitano. Uma posição equivalente é defendida por Scheid ${ }^{2}$ (2007 apud BARRERO, 2009, p. 29-30), quando ele alega que

somente a partir de uma perspectiva metropolitana ou de região urbana que aposta no restabelecimento da coerência entre o espaço funcional e o âmbito político-administrativo, por exemplo, através da criação de uma única autoridade metropolitana, os processos de planejamento público e de prestação de serviços podem funcionar com o máximo grau de eficiência e equidade.

Neste artigo argumenta-se contra o ponto de vista dos aspirantes a um sistema amplo de governança ou governo metropolitano, centralizador e orientado exclusivamente por princípios de racionalidade técnica e funcional, unilateralmente impostos aos municípios por níveis governamentais superiores, por basicamente dois motivos: primeiro, por suas implicações negativas para a vitalidade da democracia local e, segundo, por sua inviabilidade em vista do legado histórico, do contexto estrutural e sociopolítico que tornam tais tentativas insustentáveis pelo menos em longo prazo. Na seção final, enfim, argumenta-se em favor da governança em rede, sendo os arranjos institucionais concebidos como resultado de um processo contínuo de cooperação, que respeite a autonomia local e a pluralidade de atores sociais locais.

\section{Experiências de governança metropolitana na América Latina}

A tendência geral das metrópoles latino-americanas com seus arranjos institucionais frágeis ou até inexistentes na escala metropolitana parece apenas parcialmente contrariada pelas experiências de Caracas, Quito e Bogotá, as quais, segundo Klink (2005, p. 171), podem ser "classificadas como exceções à ausência generalizada de marcos para a governabilidade metropolitana na América Latina".

A seguir, pretende-se confrontar esse grupo de casos latino-americanos com um arcabouço institucional e legal formalizado em nível metropolitano, com outro grupo caracterizado por condições institucionais mais frágeis, no qual, porém, as articulações intermunicipais nas regiões são primordialmente resultado de iniciativas locais de governança. Quanto ao primeiro grupo, darei uma olhada mais detalhada no caso da Colômbia, um Estado unitário onde, em tese, o Estado nacional dispõe de autoridade legal para impor soluções institucionais às unidades subnacionais. Quanto ao segundo grupo, enfatizamos a experiência brasileira caracterizada por um federalismo que atribui ampla autonomia aos municípios, dificultando ingerências por parte da União ou dos estados. 0 confronto entre os dois casos tem por objetivo ilustrar possibilidades e limitações das duas condições, discutir alguns dilemas institucionais daí provenientes, para destarte sustentar o argumento principal do artigo em favor de uma governança metropolitana em rede.

Entre os casos com "ordenamentos de governabilidade" (LEFÈVRE, 2005, p. 252) criados em âmbito nacional, abordamos especificamente o caso colombiano em que um arcabouço institucional formal é definido e imposto aos municípios pelo Estado

2 SCHEID, H. A. Tres propuestas para una relación efectiva entre las escalas regional y local en materia de ordenación del territorio. In: FARINÓS, J.; ROMERO, J. (Comp.). Territorialidad y buen gobierno para el desarrollo sostenible. Nuevos principios y nuevas políticas en el espacio europeo. Valencia: Universidad de Valencia, 2007. 
republicano e unitário (KLINK, 2005; BARRERO, 2009). De acordo com artigo I da Constituição colombiana de 1991, "Colômbia é um Estado social de direito, organizado em forma de República unitária, descentralizada, com autonomia de suas entidades territoriais...". A estrutura político-administrativa da Colômbia é constituída pelos departamentos com competências limitadas e pelos municípios, que são responsáveis pela prestação de serviços públicos básicos, sendo resultado de um processo de descentralização conduzido pelo governo nacional (ROSENBAUM; RODRIGUEZ-ACOSTA, 2005).

Estabelecido por lei em 1978, e revisado em 1994, o arcabouço institucional para as regiões metropolitanas define claramente as funções e responsabilidades que deveriam ser criadas para as regiões metropolitanas: um Conselho Metropolitano ("Junta Metropolitana"), integrado pelos prefeitos de cada um dos municípios metropolitanos e presidido pelo prefeito da metrópole ou maior cidade, o governador do departamento, um representante do Conselho Municipal da cidade principal e mais um representante de um dos Conselhos Municipais dos demais municípios; o prefeito metropolitano como dirigente e ao mesmo tempo chefe da administração metropolitana, um cargo destinado ao prefeito da maior cidade; um gerente metropolitano como representante legal da área; e, finalmente, um Conselho de Planejamento Metropolitano (BARRERO, 2009). As regiões metropolitanas são responsáveis pelo planejamento de uma vasta gama de serviços urbanos, incluindo os aspectos financeiros, sendo o marco legal vinculativo para os municípios (KLINK, 2005).

Por não haver alternância de poder entre os diferentes prefeitos da região, sendo o gabinete do prefeito metropolitano sempre ocupado pelo prefeito da capital, resistência e conflitos têm sido comuns entre a cidade polo e os municípios circundantes, economicamente mais fracos. Em vista das amplas competências da região metropolitana e em virtude da forte posição do prefeito metropolitano em relação ao Conselho, cujas decisões dependem da aprovação do prefeito, há muitas críticas, sobretudo por parte daqueles municípios que contestam a constitucionalidade desse regime jurídico por supostamente violar a autonomia local e por não respeitar as interdependências locais (KLINK, 2005).
No entanto, apesar do arcabouço legal existente em âmbito nacional, estruturas institucionais correspondentes foram implementadas até hoje em apenas seis das regiões metropolitanas de menor relevância nacional, e essas, inclusive, são anteriores à legislação vigente de 1994. "Assim, as principais regiões urbanas da Colômbia não contam com instituições para manejar assuntos supramunicipais como a prestação de serviços públicos ou a execução de obras regionais", sendo inclusive o caso da região metropolitana de Bogotá (BARRERO, 2009, p. 16). Bogotá revela a insuficiência de iniciativas nacionais legais e a grande importância da dinâmica sociopolítica local, das condições estruturais institucionais, bem como das experiências históricas que podem facilitar ou, como neste caso, impedir o desenvolvimento institucional.

Cabe destacar que a centralização metropolitana costuma ser defendida com o argumento de uma suposta superioridade quanto à racionalidade técnica ou funcional. Isso é evidente no que diz respeito à Lei n. 128, de 1994, na qual o legislador colombiano exige uma "administração coordenada [...] para a programação e coordenação de seu desenvolvimento e para a prestação racional de seus serviços públicos"3. Enquanto as instâncias governamentais superiores insistem na racionalidade técnica, tentando impor restrições às autoridades locais, os governos locais, em contraste, desconfiam de tais esforços suspeitando de um assalto à sua autonomia local.

No caso específico de Bogotá, a experiência histórica com a criação do Distrito Federal de Bogotá, durante os anos 1940 e 1950, parece na origem desta desconfiança geral. Naquela época, alguns bairros periféricos e municípios vizinhos foram incorporados ao distrito federal, perdendo, com isso, sua autonomia e tornando-se meros distritos locais.

Portanto, a criação de uma área metropolitana é considerada por parte dos municípios na Sabana como o primeiro passo para se tornar um distrito local, razão essa porque a maioria dos municípios não simpatiza com essa alternativa por violar diretamente sua autonomia local (BARRERO, 2009, p. 17).

Pela mesma razão, nenhuma das seis regiões metropolitanas tem feito uso da possibilidade de

\footnotetext{
${ }^{3}$ Legislação citada segundo Barrero (2009, p. 6) e Martinez (2009, p. 2).
} 
se tornar um distrito, embora isso implicasse maior importância política e autonomia fiscal. Barrero (2009) considera responsável por essa omissão a baixa flexibilidade dessa estrutura institucional, prejudicando os direitos políticos e territoriais das localidades. No atual contexto democrático, com direitos constitucionais garantidos aos governos locais, esse tipo de subordinação institucional imposta parece uma forma pouco promissora para alcançar cooperação intermunicipal na escala metropolitana.

Cabe também frisar a falta de participação dos atores da sociedade civil "no desenho e execução de um sistema de governança metropolitana" (KLINK, 2005, p. 176). Esse item, porém, não é uma particularidade do caso colombiano, e vamos voltar a essa questão em nossa seção final sobre as perspectivas da governança metropolitana em rede. Por enquanto, é importante registrar os limites de arcabouços institucionais metropolitanos, impostos unilateralmente, se as condições e demandas específicas dos municípios menores e da sociedade civil não são levadas em conta.

Isso é especialmente relevante se, como no caso de Bogotá, uma cidade central extremamente dominante defronta um reduzido número de municípios pequenos e econômica e politicamente frágeis. A avaliação de Gerardo Ardila (2010, p. 9) é tão decepcionante quanto clara: "Os processos de busca de um consenso regional, desde as associações de municípios até a Mesa Redonda de Ordenamento do Território, bem como todas as outras tentativas realizadas desde 1959, fracassaram". Ele responsabiliza a desconsideração do caráter político da governança metropolitana por esses fracassos e o foco unilateral dado nos aspectos meramente técnicos de tais acordos.

Por outro lado, é notável que recentemente o foco da discussão tenha se deslocado do âmbito metropolitano a uma escala maior, um âmbito regional, processo fortemente impulsionado por interesses econômicos e instâncias governamentais superiores. Em recente debate organizado pelo Instituto de Estudos Urbanos da Universidade Nacional da Colômbia (IEU, 2010), três possíveis arranjos institucionais de extensão territorial progressiva foram discutidos: a Cidade Região, a Região da Capital e a Região Central, revelando, porém, o surgimento dos mesmos conflitos, divergências e oposições.
De um lado, havia os representantes de Bogotá e das autoridades governamentais superiores empenhando-se em favor de maior autoridade centralizada, a fim de garantir racionalidade técnica, e de outro, os prefeitos dos municípios menores desconfiados e preocupados com a manutenção de sua autonomia. Não obstante, há definitivamente um progresso a ser registrado, uma vez que tais fóruns organizados para pensar e negociar estratégias de integração regional permitem uma discussão pública mais ampla, na medida em que o público geral está sendo envolvido e atores não governamentais estão sentados na mesa discutindo e negociando soluções conjuntas com os agentes dos governos apesar da distância que ainda se percebe diante das expectativas de um "ordenamento [territorial] que vincula os cidadãos às atividades públicas exercidas" (GTZ; FESCOL, 2003, p. 13), distância essa que tem caracterizado a discussão colombiana sobre descentralização e reordenamento territorial das últimas décadas.

Uma das expectativas dos profissionais do planejamento territorial era a Lei Orgânica de Ordenamento Territorial (LOOT), anunciada na Constituição de 1991 para estruturar o ordenamento e o desenvolvimento territorial no país, que foi finalmente aprovada pelo congresso no ano passado, depois de tramitar durante 20 anos nas instituições competentes. No entanto, de acordo com Barreneche (2012, p. 18), a lei não cumpriu os objetivos de fortalecer os municípios e a organização territorial, mas acabou se transformando em um mero mecanismo para as diferentes unidades territoriais se qualificarem para acessar os recursos da Lei dos Royalties: "Essa lei [a LOOT] somente resolve definições menores sobre os mecanismos de formação de parcerias e reduz a organização territorial à criação de instâncias habilitadas para acessar os recursos dos royalties".

Apesar das resistências por parte do governo nacional a uma descentralização e um reordenamento territorial efetivo, observa-se iniciativas colaborativas interessantes oriundas das próprias regiões, frequentemente, como no caso de Medellín, em função do protagonismo do município polo que assume um papel de liderança no processo de desenvolvimento e integração regional (RESTREPO, 2006). Com uma estrutura institucional diversificada em âmbito metropolitano e regional - como 
a própria Área Metropolitana do Vale de Aburrá, a Rede de Cooperação Internacional de Antioquia ou a Agência de Cooperação e Investimento de Medellín e Área Metropolitana -, a cidade de Medellín, em cooperação com seus municípios fronteiriços, o governo departamental de Antioquia e outros parceiros da inciativa privada e da sociedade civil organizada, se destaca hoje pela cooperação regional em vários temas, tendo conseguido criar inclusive uma política pública de cooperação regional para Medellín e região (ACI, 2011).

De forma geral, podemos afirmar que as experiências consideradas sugerem que, apesar de supostas melhores possibilidades de condução centralizada num Estado unitário como a Colômbia, os limites são dados pela própria dinâmica local e regional, pelo grau de conscientização quanto à necessidade de ações coletivas, e pela capacidade de mobilização política. Dessa maneira, cabe ao município polo um papel fundamental tanto na promoção de confiança intermunicipal e de articulação intergovernamental como em relação à inclusão da sociedade no processo de integração regional, como fatores cruciais de êxito.

Dentre as metrópoles do segundo grupo, segundo Lefèvre (2005), temos Santiago de Chile, sem qualquer tipo de ordenação governamental, e Buenos Aires, onde predominam agências com fins especiais que foram criadas por inciativa dos governos nacionais e provinciais, marginalizando, no entanto, os próprios governos locais da região metropolitana no processo de estruturação institucional. Um deficit de participação e transparência coloca os municípios numa situação de dependência da sua capacidade de negociar e trocar favores com os órgãos superiores, gerando condições muito desfavoráveis para o estabelecimento de um efetivo regime de governança (KLINK, 2005).

A situação da Argentina, embora apresente semelhanças quanto à fragilidade do quadro institucional, difere de forma muito clara do Brasil, onde os municípios desfrutam de uma ampla autonomia local desde a promulgação da Constituição de 1988. No processo de democratização, as regiões metropolitanas e suas agências de planejamento, criadas durante o regime militar em 1973, foram extintas, enfraquecidas ou reduzidas a meros órgãos administrativos, sem poder político e competências para intervir de forma eficaz nos assuntos locais perante os municípios providos de ampla autonomia municipal pela Constituição de 1988 (SOUZA, 2007). Visto que "os instrumentos e mecanismos de gestão adotados [no período pós-Constituição de 1988] eram frágeis perante um processo de metropolização que se intensificava e se transformava" (SANTOS Jr., 2009, p. 6), o resultado foi a predominância do "municipalismo em detrimento das formas compartilhadas de gestão territorial" (ABRUCIO, 2005, p. 49).

Embora 23 Regiões Metropolitanas tenham sido institucionalizadas até hoje por legislações estaduais, tal fato "não significa, necessariamente, que nessas RMs a governança metropolitana esteja em operação" (SOUZA, 2007, p. 255). Pelo menos, existem no Brasil práticas muito distintas de governança metropolitana, até porque na Constituição as competências relativas à regulamentação têm sido atribuídas aos estados.

Entretanto, "os constituintes de 1988 [...] decidiram deixar a governança metropolitana em um vazio político, institucional e administrativo, restringindo a reforma urbana à criação de mecanismos participativos na esfera local" (SOUZA, 2007, p. 238) e, até hoje, a questão metropolitana vem sendo excluída das reformas estatais implementadas nas últimas décadas no Brasil, revelando um "desinteresse político na gestão pública das áreas metropolitanas" (RIBEIRO, 2004, p. 22).

0 federalismo brasileiro privilegiou relações de competitividade entre os diferentes níveis governamentais em detrimento de estruturas de cooperação, o que é particularmente verdadeiro para as regiões metropolitanas (SOUZA, 2007). Abrucio (2005, p. 49) fala de um "federalismo compartimentalizado, em que cada nível de governo procurava encontrar o seu papel específico e não havia incentivos para o compartilhamento de tarefas e a atuação consorciada". Para a maioria dos cientistas sociais, a ampla autonomia local é vista como um dos sérios impedimentos para a consolidação da governança metropolitana no Brasil (AZEVEDO; GUIA, 2000; ROLNIK; SOMEKH, 2003; SOUZA, 2007; SANTOS Jr., 2009). A atuação das Regiões Metropolitanas e de suas agências de planejamento, criadas e conduzidas pelos estados já durante o regime militar, foi marcada por "conflitos e tensões nas relações inter e intragovernamentais, aprofundando, portanto, as clivagens federativas e os problemas de cooperação" 
(SOUZA, 2007, p. 236). Celina Souza argumenta que "as escolhas institucionais relativas à gestão das RMs, moldadas pela centralização, autoritarismo e pela ausência de mecanismos de cooperação entre as esferas governamentais, marcaram sua trajetória durante o regime militar e tornaram quase impossível sua sobrevivência após a redemocratização" (SOUZA, 2007, p. 257).

No entanto, é, por outro lado, bastante notável que, apesar das falhas na promoção da cooperação por parte das instâncias governamentais superiores, têm surgido iniciativas dos próprios governos locais visando melhorar a cooperação intermunicipal nas regiões metropolitanas. Muito bem-sucedidos se revelaram os consórcios intermunicipais enquanto parceria entre administrações locais para o enfrentamento de problemas comuns como a coleta ou o tratamento de resíduos sólidos, a prestação de serviços nas áreas de saúde ou meio ambiente, compartilhando recursos e esforços em favor de soluções coletivas. Tornou-se uma estratégia cada vez mais importante em vista da fragilidade das autoridades regionais, sem comprometer a autonomia municipal. Esses consórcios estão abertos à participação livre dos seus membros e todas as atividades devem ser aprovadas pelo conselho de administração composto pelos prefeitos dos municípios envolvidos (VAZ, 1997).

Outra iniciativa promissora na busca de novas práticas colaborativas de governança em regiões metropolitanas são os chamados comitês de bacias hidrográficas, compostos por representantes dos governos estaduais e municipais, da sociedade civil e do setor empresarial, que são conjuntamente responsáveis pela gestão e pelo planejamento das bacias hidrográficas. Apesar dos limites dessas experiências que se referem à "prevalência de lógicas de gestão que ainda centram, na maioria dos casos, uma forte superioridade do componente técnico como referencial de controle do processo" (JACOBI, 2005 , p. 83), elas se destacam pela inserção de atores não governamentais em processos de governança, favorecendo a configuração de um "espaço de articulação, de negociação, de debate de problemas [que] abre espaço para a expressão e defesa dos interesses difusos" (JACOBI, 2005, p. 83).

Por fim, cabe mencionar a experiência de cooperação intermunicipal do "Grande ABC Paulista", onde os próprios municípios da região se aliaram para criar conjuntamente uma Câmara e Agência de Desenvolvimento com o objetivo de desafiar o declínio industrial sofrido pela região nas últimas décadas e os problemas relacionados com o aumento da pobreza, o desemprego e a deterioração geral da qualidade de vida (KLINK, 2005; SOUZA, 2007). Apesar das inúmeras dificuldades e reveses sofridos desde que a iniciativa se iniciou na década de 1990, essa "mobilização de baixo" tem contribuído, de acordo com Klink (2005, p. 160-161), para iniciar "um processo através do qual a região começou a enfatizar progressivamente a sua identidade econômica, política e cultural". Assim, Klink chega a concluir que "a experiência de um planejamento participativo 'de baixo para cima' e 'multisetorial', que envolve atores públicos e privados, tem demonstrado ser uma alternativa com probabilidades de sucesso, frente ao atual sistema brasileiro de regiões metropolitanas administrativas" (KLINK, 2005, p. 163).

Mas para além das experiências de articulação intermunicipal para a solução de problemas comuns, da realização de tarefas conjuntas mediante os consórcios intermunicipais, bem como da criação de institucionalidades complexas e multifinalitárias, porém territorialmente restritas, como no caso da região do $\mathrm{ABC}$, existem no Brasil outras experiências promissoras que buscam aliar arranjos institucionais territorialmente abrangentes, com atuação multifinalitária e maior envolvimento da sociedade civil. Conforme estudo recente do Observatório das Metrópoles, merecem destaque os casos de Belo Horizonte, onde vem se consolidando, no decorrer das últimas décadas, "uma estrutura mais complexa de gestão que inclui Assembleia Metropolitana, Conselho Deliberativo de Desenvolvimento Metropolitano, Agência de Desenvolvimento Metropolitano", com o reforço ainda de um Grupo de Governança Metropolitana, de um Fórum Metropolitano e de

\footnotetext{
4 Trata-se de uma associação de sete municípios - Santo André, São Bernardo do Campo, São Caetano do Sul, Diadema, Mauá, Ribeirão Pires e Rio Grande da Serra - da parte sudeste da Região Metropolitana de São Paulo, possuindo o maior polo automobilístico do Brasil, com uma população de 2,2 milhões de habitantes (ROLNIK; SOMEKH, 2003).
} 
uma Associação dos Municípios da Região Metropolitana de Belo Horizonte" (SANTOS Jr., 2009, p. 8), e o de Recife, "onde funcionam, num Sistema Gestor Metropolitano, um Conselho de Desenvolvimento, uma Fundação de Desenvolvimento e uma secretaria executiva de apoio técnico" (SANTOS Jr., 2009, p. 8), além de um Fundo Metropolitano para financiamento de projetos e serviços públicos comuns na região.

A recente fase de reformas inovadoras da gestão metropolitana se caracteriza pelo fortalecimento de estruturas intergovernamentais e da ampliação das possibilidades de participação da sociedade civil e da iniciativa privada nos processos e estruturas institucionais. No caso de Belo Horizonte, além do fortalecimento institucional no âmbito estatal, temos com o Fórum Metropolitano da RMBH e o Fórum Mineiro de Reforma Urbana espaços importantes de articulação Estado/sociedade, que permitem uma abertura do debate sobre os rumos das aglomerações urbanas para a sociedade civil. Já através da Assembleia Metropolitana os poderes legislativos municipais acabam, por meio de seus Presidentes, obtendo uma representação na estrutura institucional da região metropolitana, embora a sociedade civil continue excluída "dos órgãos de gestão institucionalizados da RMBH (Assembleia Metropolitana, Conselho Deliberativo de Desenvolvimento Metropolitano, Agência de Desenvolvimento Metropolitano)" (SANTOS Jr., 2009, p. 58), onde as decisões decisivas são tomadas.

Quanto ao caso brasileiro, podemos, portanto, constatar de forma geral uma heterogeneidade bastante grande de arranjos institucionais nas diferentes regiões em virtude da falta de uma legislação nacional e avanços em relação ao fortalecimento das relações intergovernamentais e entre Estado e sociedade naquelas regiões com atuação importante do município polo, do governo estadual, bem como uma pressão efetiva por parte da sociedade civil organizada.

\section{Governança em rede: uma abordagem para lidar com o dilema metropolitano na América Latina?}

No debate internacional, o novo regionalismo ganhou influência nos últimos anos, mudando a atenção das estruturas de governo para as de "governança", da concepção de uma condução hierárquica das áreas metropolitanas para práticas de cooperação horizontal e voluntária (BLATTER, 2006). Na América Latina, em vista da fragilidade das estruturas metropolitanas existentes, ainda predominam, entre planejadores e entre pesquisadores e teóricos da questão metropolitana, posições favoráveis a uma governança metropolitana mais centralizada, ou até "governos metropolitanos", garantidos preferencialmente por uma legislação nacional ou estadual. Supõe-se que essa seria a maneira mais eficaz de lidar com o desafio metropolitano. $\mathrm{O}$ argumento da racionalidade técnica e funcional costuma sobrepor-se ao argumento da autonomia local e da descentralização.

Isso é particularmente o caso em regiões metropolitanas monocêntricas, como em Bogotá, onde uma poderosa cidade central é cercada por municípios relativamente pequenos, dotados de recursos escassos, enquanto que em regiões mais policêntricas - muito raras na América Latina - as condições de cooperação parecem mais favoráveis. 0 caso da cooperação intermunicipal no Grande ABC paulista revela claramente tais possibilidades, embora essa cooperação seja restrita a apenas uma parte da região metropolitana de São Paulo. $\mathrm{Na}$ verdade, a própria dificuldade de encontrar formas de governança para toda a região metropolitana de São Paulo parece ter favorecido a união entre os municípios do $\mathrm{ABC}$, corroborando com a nossa avaliação quanto aos limites da integração em regiões metropolitanas monocêntricas, de um lado; e, de outro, em relação às oportunidades promissoras relacionadas a iniciativas que emergem de baixo por parte dos municípios. Pequenos municípios, confrontados com suas condições locais desfavoráveis, sentem-se compelidos e/ou estimulados a cooperar com seus vizinhos para poder resolver problemas comuns.

A relativa igualdade entre os municípios e a construção de relações de confiança, bem como a consciência quanto às interdependências existentes, são elementos decisivos de sucesso. Essas condições são muito mais difíceis de se alcançar em regiões monocêntricas e dificilmente podem ser asseguradas por agências ou governos suprametropolitanos. Avanços no campo da ação coletiva dependem extraordinariamente da disposição da parte mais forte em adotar uma postura de solidariedade com os 
municípios mais fracos, dentro de uma perspectiva de "interesse bem compreendido" (Tocqueville); isto é, o reconhecimento de que a cooperação é a única forma de solucionar de forma sustentável os problemas coletivos. 0 caso de Medellín, apesar de se tratar de uma região com um desequilíbrio menos extremo do que Bogotá, demonstra a central importância do papel protagonista do município polo.

A maneira tradicional de tentar promover a cooperação pela força da lei ou por meio de incentivos financeiros pode até convencer as autoridades locais a fazer o que é necessário para obter os recursos em tempos de escassez financeira e de elevada concorrência entre as autoridades locais, mas dificilmente são medidas adequadas para mobilizar sinergias baseadas em parcerias e na cooperação, tal como previsto no conceito de governança pública ${ }^{5}$.

Celine Souza (2007) chama a atenção para outro aspecto importante: a crescente importância de novos atores, como os conselhos comunitários ou os organismos multilaterais e supranacionais - aqui deveríamos acrescentar, ainda, os movimentos sociais e as organizações não governamentais -, nas arenas políticas urbanas e metropolitanas, que influenciam crescentemente as relações intra e intergovernamentais.

Tal fato se torna ainda mais relevante no atual contexto da sociedade da informação, no qual a rede tornou-se o princípio básico de organização da sociedade civil, aumentando cada vez mais a busca pela interação com autoridades estatais e com a iniciativa privada (SCHERER-WARREN, 2006). A sociedade civil pode adquirir um papel cada vez mais importante nos processos de articulação política em regiões metropolitanas, ao exercer pressão sobre os governos para que estes participem de forma efetiva em um diálogo aberto com a sociedade, convencendo-os da necessidade de se estabelecer mecanismos institucionais para permitir maior interação e participação.

Tais inovadoras disposições institucionais também são importantes para avançar na integração vertical entre as estruturas de governança na escala metropolitana, com aqueles em nível municipal, das comunidades ou bairros. Como Lefèvre (2005, p. 256-257) coloca, "A criação de corpos 'supramunicipais' deve ser acompanhada por instrumentos para vincular o sistema metropolitano de tomada de decisão com o nível local, seja este em nível municipal ou de vizinhança". Essa vinculação possível, entretanto, depende de um triplo desafio: além de um planejamento com instrumentos adequados de integração, hoje o foco das preocupações governamentais, é preciso incentivar e fomentar processos de articulação em rede entre poder público e os demais agentes societais e, finalmente, criar representações políticas e populares em nível metropolitano, como conselhos e até parlamentos metropolitanos. Mesmo nos casos como os de Belo Horizonte ou Medellín, onde se avançou na criação de espaços de articulação Estado/sociedade na gestão metropolitana, tem-se resistido a uma efetiva participação da sociedade e do cidadão nos processos de tomada de decisão por meio de representações populares.

Quanto a esse assunto, é muito importante a superação dos discursos tanto do gerencialismo urbano quanto da racionalidade exclusivamente técnica, para abrir as arenas de tomada de decisão à disputa política legítima. Em contraposição ao conceito da "democracia despolitizante", de Philip Pettit (2004), que vê na despolitização da democracia um processo positivo e favorável ao fortalecimento da deliberação política, parece-nos mais pertinente, diante do contexto empírico da América Latina, interpretar a despolitização antes como um processo de retirada dos cidadãos das arenas políticas locais, tendente a reforçar a tecnocracia, bem como uma situação em que uma população socialmente frágil continua dependente do Estado e na qual a relação entre governantes e governados é baseada fundamentalmente em estruturas políticas clientelistas e patrimonialistas.

0 papel das organizações da sociedade civil e sua inserção nas redes de governança metropolitana tornam-se cruciais neste contexto, considerando

\footnotetext{
5 Na verdade, trata-se aqui, grosso modo, de duas vertentes distintas de governança: a primeira, inspirada nos princípios da escolha racional, partindo do pressuposto de que os governos agem e tomam decisões baseados em uma racionalidade instrumental-material e na busca da eficiência; e a segunda, apostando nas possibilidades do processo argumentativo, da centralidade da solidariedade e da confiança nas relações de governança, bem como na busca de maior equidade na sociedade, a perspectiva adotada neste trabalho. Ver p. ex. o artigo introdutório em Bevir (2009).
} 
com Oakerson (2004, p. 20) que "a governança é o trabalho de pessoas de dentro e de fora de governos" e que progresso, neste sentido, parece consequência da força organizativa e política da sociedade civil, e muito menos simples produto da vontade governamental. Portanto, o caminho em direção a uma efetiva governança em rede, necessária para superar os dilemas dos problemas interjurisdicionais, interescalares e interdisciplinares, pressupõe um papel ativo tanto da sociedade civil quanto dos governos municipais, cooperando uns com os outros, para pressionar no sentido de que sejam criadas as arenas deliberativas necessárias para um enfrentamento aberto, transparente e democrático dos problemas metropolitanos. Isso inclui, afinal, a criação de representações populares em nível metropolitano como condição básica para a politização das grandes questões estruturais das metrópoles. As autoridades eleitas precisam se conscientizar e enxergar a sociedade civil, os movimentos sociais e os cidadãos como efetivos parceiros e atores políticos cruciais da governança metropolitana. Isso significa que uma governança democrática com potencial de enfrentamento dos grandes problemas socioambientais das regiões metropolitanas envolve a necessidade da recuperação da dimensão essencialmente política da governança metropolitana e, com isso, do fomento de um efetivo espaço público na escala metropolitana, sendo este, e não os gabinetes dos políticos e gestores, a esfera essencial da ação política e democrática.

\section{Referências}

ABRUCIO, F. L. A coordenação federativa no Brasil: a experiência do período FHC e os desafios do governo Lula. Revista de Sociologia e Política, v. 24, p. 41-67, jun. 2005.

AGENCIA DE COOPERACIÓN E INVERSIÓN DE MEDELLIN Y EL ÁREA METROPOLITANA - ACI. Medellín, la región y el mundo: uma mirada de la Agencia de Cooperación e Inversión de Medellín y el Área Metropolitana - ACI. Medellín: ACI, 2011. Disponível em: <http://www.acimedellin.org/es/Publicaciones.aspx>. Acesso em: 12 abr. 2012 .
ARANTES, O.; VAINER, C.; MARICATO, E. (Org.). A cidade do pensamento único: desmanchando consensos. Petrópolis: Vozes, 2000.

ARDILA, G. Bogotá-Sabana: ¿Gobernabilidad posible? Foro Ambiental Nacional: Documento de políticas públicas, Bogotá, n. 30, p. 1-9, 2010. Disponível em: <http:// library.fes.de/pdf-files/bueros/kolumbien/07255.pdf>. Acesso em: 21 jan. 2011.

ARRETCHE, M. T. S. Políticas sociais no Brasil: descentralização em um Estado federativo. Revista Brasileira de Ciências Sociais, v. 14, n. 40, p. 111-141, 1999.

AZEVEDO, S. de; GUIA, V. R. dos M. Governança metropolitana e reforma do Estado. Revista Brasileira de Estudos Urbanos e Regionais, n. 3, p. 131-144, nov. 2000.

BARLOW, M. Centralization and decentralization in the governing of cities and metropolitan regions. In: BENNETT, R. J. (Ed.). Local government and market decentralization: experiences in industrialized, developing, and former Eastern bloc countries. Tokyo: United Nation University Press, 1994. p. 319-332.

BARRENECHE, C. S. Metropolización y regionalización: repensar el gobierno territorial en Colombia. Papeles y Coyuntura, n. 32, p. 16-21, marzo 2012. Disponível em: <http://www.papelesdecoyuntura.com/PC_32-\%20 Opini\%C3\%B3n.pdf>. Acesso em: 5 abr. 2012.

BARRERO, G. A. C. La institucionalidad metropolitan en Colombia: aplicación de la ley 128 de 1994 y otras decisiones administrativas. In: SEMINARIO DE INVESTIGACIÓN URBANO-REGIONAL, 7., 2009, Bogotá. Anais... Bogotá: Bogotá Universidad Nacional de Colombia, 2009. 1 CD, p. 1-40.

BEVIR, M. Key concepts in governance. London: Sage, 2009.

BLATTER, J. K. Geographic scale and functional scope in metropolitan governance reform: theory and evidence from Germany. Journal of Urban Affairs, v. 28, n. 2, p. 121-150, 2006.

BORJA, J. El gobierno del territorio de las ciudades latinoamericanas. Revista Instituciones y Desarrollo, n. 8/9, p. 83-142, 2001.

BRENNER, N. Metropolitan institutional reform and the rescaling of state space in contemporary Western Europe. European Urban and Regional Studies, v. 10, n. 4, p. 297-324, 2003. 
COPANS, R. Empreendedorismo urbano: entre o discurso e a prática. São Paulo: UNESP, 2005.

CUADRADO-ROURA, J. R.; GÜELL, J. M. F. Las áreas metropolitanas frente al desafío de la competitividad. In: ROJAS, E.; CUADRADO-ROURA, J. R.; GÜELL, J. M. F. (Ed.). Governar las metrópoles. Washington D.C.: Banco Interamericano de Desarrollo; Universidad de Alcalá de Henares, 2005. p. 63-125.

DAVIDOVICH, F. A "volta da metrópole" no Brasil: referências para a gestão territorial. In: RIBEIRO, L. C. de Q. (Org.). Metrópoles: entre a coesão e a fragmentação, a cooperação e o conflito. São Paulo: Fundação Perseu Abramo; Rio de Janeiro: Fase, 2004. p. 197-230.

DE MATTOS, C. A. Redes, nodos e cidades: transformação da metrópole latino-americana. In: RIBEIRO, L. C. de Q. (Org.). Metrópoles: entre a coesão e a fragmentação, a cooperação e o conflito. São Paulo: Fundação Perseu Abramo; Rio de Janeiro: Fase, 2004. p. 157-196.

FEIOCK, R. Introduction: regionalism and institutional collective action. In: FEIOCK, R. (Ed.). Metropolitan governance: conflict, competition, and cooperation. Washington D.C.: Georgetown University, 2004. p. 3-16.

FREY, K. Governança urbana e participação pública. RACeletrônica: Revista de Administração Pública, v. 1, n. 1, p. 136-150, 2007.

GILBERT, A. Is urban development in the Third World sustainable? In: GIRARD, L. F. et al. (Ed.). The human sustainable city: challenges and perspectives from the habitat agenda. Aldershot, Burlington: Ashgate, 2003. p. 71-88.

GRINDLE, M. S. Going local: decentralization, democratization, and the promise of good governance. Princeton, New Jersey: Princeton University Press, 2007.

GROTE, J. R.; GBIKPI, B. (Ed.). Participatory governance: political and societal implications. Opladen: Leske \& Budrich, 2002.

GTZ; FESCOL. Introducción. In: BECKER, A.; CHICA, C.; CÁRDENAS, M. E. (Ed.). Ordenamiento territorial: reivindicación de la descentralización para el desarollo. Bogotá: GTZ; FESCOL, 2003.

HAMBLETON, R.; SAVITCH, H. V.; STEWART, M. (Ed.). Globalism and local democracy: challenge and change in Europe and North America. New York: Palgrave Macmillan, 2002.
HEINELT, H. Demokratie jenseits de Staates. BadenBaden: Nomos, 2008.

INSTITUTO DE ESTUDIOS URBANOS - IEU. Foro Gobernabilidad Regional: los municipios y Bogotá. Debates de Gobierno Urbano. Bogotá: Universidad Nacional de Colombia, June 2010. p. 1-12. Disponível em: <http://www.institutodeestudiosurbanos.com/descargas/doc_download/1006-conclusiones-foro-ii-gobernabilidad-regional-los-munipios-y-bogota-.html>. Acesso em: 5 jan. 2011.

JACOBI, P. R. Comitês de bacias hidrográficas: o que está em jogo na gestão compartilhada e participativa. In: DOWBOR, L.; TAGNIN, R. A. (Ed.). Administrando a água como se fosse importante. São Paulo: Senac, 2005. p. 81-88.

KLINK, J. Perspectivas recientes sobre la organización metropolitana: funciones y governabilidad. In: ROJAS, E.; CUADRADO-ROURA, J. R.; GÜELL, J. M. F. (Ed.). Gobernar las metrópolis. Washington D.C.: Banco Interamericano de Desarrollo; Universidad de Alcalá de Henares, 2005. p. 127-191.

LEFÈVRE, C. Governabilidad democrática de las áreas metropolitanas. In: ROJAS, E.; CUADRADO-ROURA, J. R.; GÜELL, J. M. F. (Ed.). Gobernar las metrópolis. Washington D.C.: Banco Interamericano de Desarrollo; Universidad de Alcalá de Henares, 2005. p. 195-261.

MARTINEZ, J. C. C. Competencias metropolitanas: la atribución inconstitucional del Alcalde metropolitano. In: SEMINARIO DE INVESTIGACIÓN URBANO-REGIONAL, 7., 2009, Bogotá. Anales... Bogotá: Universidad Nacional de Colombia. 1 CD, p. 1-20.

MELO, M. A. Crise federativa, guerra fiscal e "hobbesianismo municipal": efeitos perversos da descentralização? São Paulo em Perspectiva, v. 10, n. 3, p. 11-20, 1996.

OAKERSON, R. J. The study of metropolitan governance. In: FEIOCK, R. C. (Ed.). Metropolitan governance: conflict, competition, and cooperation. Washington D.C.: Georgetown University Press, 2004.

ORGANISATION FOR ECONOMIC CO-OPERATION AND DEVELOPMENT - OECD. Cities for citizens: improving metropolitan governance. Paris: OECD, 2001.

PETTIT, P. Depoliticizing democracy. Ratio Juris, v. 17, n. 1, p. 52-65, 2004. 
REICHL, A. J. Rethinking the dual city. Urban Affairs Review, v. 42, n. 5, p. 659-687, 2007.

RESTREPO, C. I. Medellín una ciudad que se transforma. In: ESTEVE, J. M. P.; PARICIO, A. F. (Ed.). La gobernanza democrática: un nuevo enfoque para los grandes retos urbanos y regionales. Andalucia: Consejería de Gobernación; Dirección General de Administración Local, 2006. Disponível em: <http://www.aeryc.org/correspondencia/documents2010/documents/PUB\%20BOGOTA\%20 JA \% 20 G O B E R N A N Z A \% 20 DE M O CRAT I C A, \% 20 NUEVO\%20ENFOQUE\%20RETOS\%20URBANOS\%20 Y\%20REGIONALES.pdf>. Acesco en: 20 abr. 2012.

RIBEIRO, L. C. de Q. A metrópole: entre a coesão e a fragmentação, a cooperação e o conflito. In: RIBEIRO, L. C. de Q.; AZEVEDO, S. de; SANTOS Jr., O. A. dos (Org.). Metrópoles: entre a coesão e a fragmentação, a cooperação e o conflito. São Paulo: Fundação Perseu Abramo; Rio de Janeiro: Fase, 2004. p. 17-40.

ROJAS, E. Governança de regiões metropolitanas da América Latina. In: MAGALHÃES, F. (Ed.). Regiões metropolitanas no Brasil: um paradoxo de desafios e oportunidades. Banco Interamericano de Desenvolvimento, 2010. Disponível em: <http://idbdocs.iadb.org/wsdocs/getdocument. aspx?docnum=36045064>. Acesso em: 25 set. 2010.

ROLNIK, R.; SOMEKH, N. Governar as metrópoles: dilemas da recentralização. In: GONÇALVES, M. F.; GALVÃO, A. C. F. (Ed.). Regiões e cidades, cidades nas regiões: o desafio urbano-regional. São Paulo: UNESP, 2003.

ROSENBAUM, A.; RODRÍGUEZ-ACOSTA, C. A. Gobierno local y la gobernabilidad de las áreas metropolitanas en América Latina. X Congreso Internacional del CLAD sobre la Reforma del Estado y de la Administración Pública, 2005. Santiago, Chile. Anales... Chile: CLAD, 2005. Disponível em: <http://www.iij.derecho.ucr.ac.cr/archivos/documentacion/inv\%20otras\%20entidades/CLAD/CLAD\%20X/documentos/rosembau.pdf>. Acesso em: 21 jan. 2011.
SANTOS Jr., O. A. dos. Arranjos institucionais para a gestão metropolitana. Relatório de Pesquisa. In: CNPq INSTITUTOS DO MILÊNIO (Ed.). Projeto Observatório das Metrópoles. Rio de Janeiro: IPPUR, 2009. Disponível em: <http://www.observatoriodasmetropoles.ufrj.br/relatorio_arranjos_gestao_metropolitana.pdf $>$. Acesso em: 20 abr. 2012.

SCHERER-WARREN, I. Das mobilizações às redes de movimentos sociais. Sociedade e Estado, v. 21, n. 1, p. 109130, 2006.

SOUZA, C. Regiões metropolitanas: reforma do regime político e vazio de governança. In: DINIZ, E. (Ed.). Globalização, Estado e desenvolvimento: dilemas do Brasil no novo milênio. Rio de Janeiro: FGV, 2007. p. 235-261.

VAINER, C. B. Lugar, região, nação, mundo: explorações históricas do debate acerca das escalas da ação política. Revista Brasileira de Estudos Urbanos e Regionais, v. 8, n. 2, p. 9-29, nov. 2006.

VAZ, J. C. Consórcios intermunicipais. Boletim DICAS - Ideias para a Ação Municipal, São Paulo, n. 97, 1997. Disponível em: <http://www.polis.org.br/uploads/448/448.pdf>. Acesso em: 23 nov. 2010.

Recebido: $13 / 01 / 2012$

Received: 01/13/2012

Aprovado: 24/04/2012

Approved: 04/24/2012 